\title{
Improving a Redox Flow Battery Working under Realistic Conditions by Using of Graphene based Nanofluids
}

\author{
Prof. Justo Lobato*[a], Dr. Esperanza Mena ${ }^{[a]}$, María Millán ${ }^{[a]}$
}

Abstract: This work reports, for the first time, the behavior of a Redox Flow Battery using nanoparticles based on graphene in the vanadium based electrolytes to act as nanofluids and working under a solar profile radiation (realistic conditions) for renewable energy storage. It has been demonstrated that the use of graphene based nanofluids improves the performance of this energy storage system and enhances the durability of the redox flow battery.

\section{Introduction}

Renewable energies are now entering markets as a result of continuous investment in their research and development. But, these technologies show some disadvantages that must be overcome such as they are intermittent, their low adaptation between the offer and demand, etc. ${ }^{[1]}$ Thus, the use of batteries as energy storage system is crucial to make these energy technologies based on renewable sources appealed to the society. Among different types of batteries, redox flow batteries (RFBs) are one of the most recent technologies and are receiving great attention due to its advantages ${ }^{[2]}$. They are composed of an electrochemical cell and two electrolyte tanks used for the anolyte and catholyte storage. This cell allows changing chemical energy into electricity and vice versa by the oxidation and reduction reactions of electrolyte employed. Moreover, the concentration of the redox species and the volume of the tanks determine the amount of stored energy and the power is determined by the rate of reaction at each electrode and their total surface area ${ }^{[2-}$ 4]. Among the different types of RFBs, the all vanadium redox flow batteries (VRFBs) are very promising energy storage system since they employ the same ion on both electrolytes but in different oxidation states minimizing the cross-contamination (in the positive tank: $\mathrm{VO}_{2}{ }^{+} / \mathrm{VO}^{2+}$ redox couple; in the negative tank: $\mathrm{V}^{2+} / \mathrm{V}^{3+}$ redox couple $)^{[2,3]}$. Nevertheless, there are some challenges that must be face up since oxygen and protons are necessary in the cathodic reaction to keep the balance of charges and the stoichiometry (Eq.1). The redox $\mathrm{V}^{+3} / \mathrm{V}^{+2}$ reaction is more reversible and its reaction kinetic is much faster than the $\mathrm{VO}^{+2} / \mathrm{VO}_{2}{ }^{+}$reaction. It is due to the positive redox reaction involve three elementary steps, one electron transfer and two proton exchanges, and several complex intermediates depending on the electrolyte $\mathrm{pH}$ and the potentials ${ }^{[5,6]}$.Besides, RFB has a relative poor energy to weight ratio $0^{[2,3]}$.

$$
\begin{aligned}
& \mathrm{VO}^{2+}+\mathrm{H}_{2} \mathrm{O} \rightarrow \mathrm{VO}_{2}^{+}+2 \mathrm{H}^{+}+\mathrm{e}^{-} \\
& \mathrm{V}^{3+}+\mathrm{e}^{-} \rightarrow \mathrm{V}^{2+}
\end{aligned}
$$

On the other hand, nanoscience and nanotechnology could hold the keys to many of the technological advancements in the energy sector. Graphene based nanomaterials are receiving a great interest in the energy storage field. Thus, the development of electroactive nanofluids (ENFs), that is, fluids containing nanoparticles able to store electrical energy, whether through redox or capacitive mechanism have been proposed recently for energy storage applications ${ }^{[7]}$ but not under practical operation conditions. Hence, in this work, for the first time, the application of graphene based nanoparticles to be part of the electrolyte of all vanadium redox flow batteries is shown to act as nanofluids in RFBs running under realistic conditions, that is, under a solar energy profile of charge of the battery to evaluate the possible benefits of their use.

\section{Results and Discussion}

As stated before, this work aims at studying the differences found in the performance of a VRFB using graphene based materials in the electrolyte (nanofluid), charged under realistic conditions, which is following the solar radiation using solar panels. In order to do this, solar radiation was monitored for seven days in a raw, in spring in Ciudad Real, Spain (38.59 N 3.55 O). The time-course of the solar radiation measured over this period is shown in Figure 1. Maximum values were reached during the first, fifth and seventh day, reaching values around $1,100 \mathrm{~W} \mathrm{~m}^{-2}$.Variability of weather conditions was not very high and this profile can be considered as representative of typical conditions at this season in the center of Spain, so it was used in this work as a typical cycle pattern of solar irradiation to evaluate the charge of the VRFB with solar radiation.

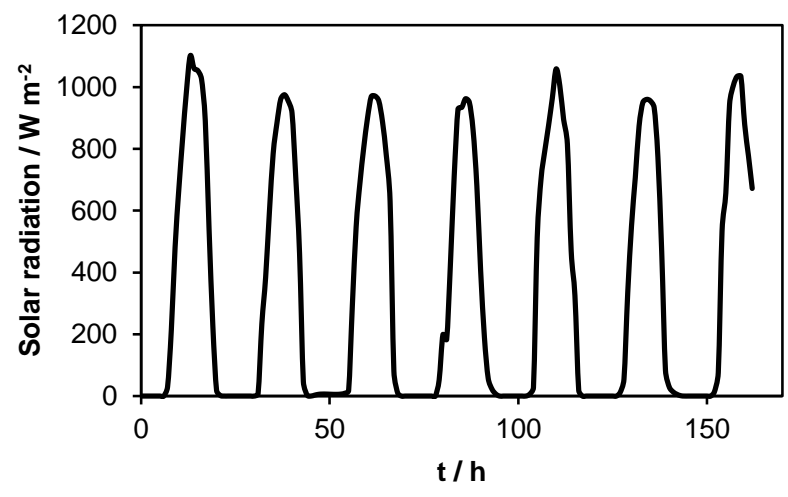

Figure 1. Solar radiation profile in Ciudad Real, Spain during seven different days $\left(30^{\text {th }}\right.$ of May to $5^{\text {th }}$ of June, 2016).

The graphene nanoplatets powders were analyze by Raman to assess the quality of this carbonaceous material. Figure 2 shows the Raman spectra of graphene nanoplatelets powders. The Raman spectra shows the characteristic peaks of graphene based material, $D$ and $G$ peaks ${ }^{[8]}$. The $D$ peak is visible at $1344 \mathrm{~cm}^{-1}$ and shows the presence of imperfections in graphitic based materials. On the other hand, the $G$ peak appears at $1591 \mathrm{~cm}^{-1}$ and it denotes the symmetryallowed graphite band. Besides, the spectra agrees with the one provided by the supplier of carbonaceous materials, Reinste ${ }^{[9]}$.

[a] Prof. Justo Lobato*, Dr. Esperanza Mena, María Millán Chemical Engineering Department, Faculty of Chemical Sciences and Technologies University of Castilla-La Mancha Enrique Costa Novella, Av. Camilo Jose Cela n 12, Ciudad Real, Spain.

E-mail: Justo.Lobato@uclm.es 


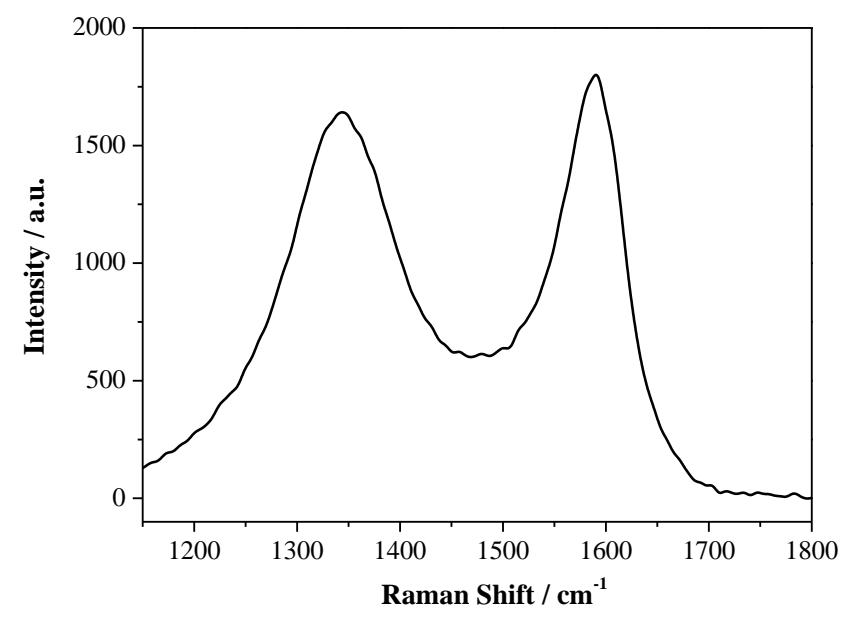

Figure 2. Raman spectra of graphene nanoplatelets powders.

Figure 3 shows the ten charge and discharge cycles applying the solar radiation profiles shown in Figure 1 to the VRFB. Using standard electrolytes and using graphene based nanofluids.

As $0.2 \mathrm{~mol}$ of electrons $\left(0.2 \mathrm{dm}^{3} \times 1 \mathrm{~mol} \mathrm{dm}^{-3}\right)$ need to be transferred across the cell in order to complete the formation of $\mathrm{V}^{4+}$ in the positive reservoir and $1 \mathrm{~mol}$ of electrons is equivalent to $26.8 \mathrm{Ah}$, hence 5.36 Ah are expected to be required. Assuming that the cell is charged at an average current of $0.98 \mathrm{~A}$, the charge of the first cycle is expected to be completed in approximately $5.5 \mathrm{~h}$. If we observed the experimental values for both tests, it can be seen that for the test using the standard electrolyte, the charge time required was $6.7 \mathrm{~h}$ which represents a difference of $21.7 \%$ with respect to the expected value. In the case of the test performed with nanoparticles, the charge time was $7 \mathrm{~h}$, which is $27.3 \%$ above the theoretical value. In comparing these results with other found in the literature, these differences can be considered as low. For example, Mohamed et al ${ }^{[10]}$ reached values of $23.7 \%$ at $20 \mathrm{~mA} \mathrm{~cm}^{-2}$.

One interesting feature that can be drawn from Figure 3 is the duration of charge-discharge cycles. As it can be observed, the experimental charge time for the first cycle is higher than the theoretical one in both experiments. It could be due to secondary reactions that place in the electrolyte as a result of vanadium ion crossover. The crossover leads to undesirable reaction in both electrodes which produce a selfdischarge in the cell increasing in this way the time of charge. These self-discharge processes can be described as follows. On the one hand, reactions 3 to 5 show the reactions once $\mathrm{V}^{+2}$ or $\mathrm{V}^{+3}$ ions cross the membrane.

$$
\begin{aligned}
& \mathrm{V}^{2+}+2 \mathrm{~V}^{5+} \rightarrow 3 \mathrm{~V}^{4+} \\
& \mathrm{V}^{3+}+\mathrm{V}^{5+} \rightarrow 2 \mathrm{~V}^{4+} \\
& \mathrm{V}^{2+}+\mathrm{V}^{4+} \rightarrow 2 \mathrm{~V}^{3+}
\end{aligned}
$$

On the other hand, the diffusion of $\mathrm{VO}^{2+}$ and $\mathrm{VO}_{2}{ }^{+}$to the negative electrolyte gives rise to the following reactions:

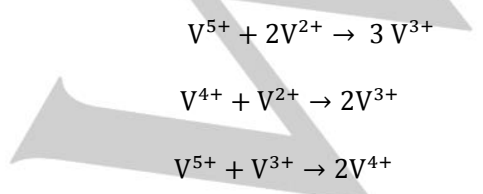

However, this is shortened in both operation modes from cycle to cycle, as expected because of the accelerated ageing caused by the membrane selected. Previous works showed higher capacity losses when the RFB is supplied with green energies such as solar or wind power [11, 12]. The higher crossover that the Nafion 117 membrane presents leads to self-discharge reactions in each electrolyte and subsequent capacity losses ${ }^{[13,14]}$. Thus, it decreased from $9.8 \mathrm{~h}$ in the first cycle (6.7 $\mathrm{h}$ charging and 3.1 of discharging) down to $2.1 \mathrm{~h}$ in the tenth cycle ( $1.7 \mathrm{~h}$ charging and $0.4 \mathrm{~h}$ discharging). A similar behavior was obtained in the other test with nanofluids, decreasing from $10.6 \mathrm{~h}$ in the first cycle ( $7 \mathrm{~h}$ charging, $3.6 \mathrm{~h}$ discharging) down to $2.6 \mathrm{~h}$ in the tenth cycle (1.9 $\mathrm{h}$ charging, $0.7 \mathrm{~h}$ discharging). But, what it must be pointed out, is that the use of nanofuids allows the use of the battery during longer period. Thus, in the case of the test with the standard electrolyte, the ten cycles of charge and discharge lasted around 51 hours while in the case of the test using the nanoparticles of graphene, the battery was operating for longer time, close to $60 \mathrm{~h}$. This means, that the degradation effect was lower in the case of the test with the nanofluids.
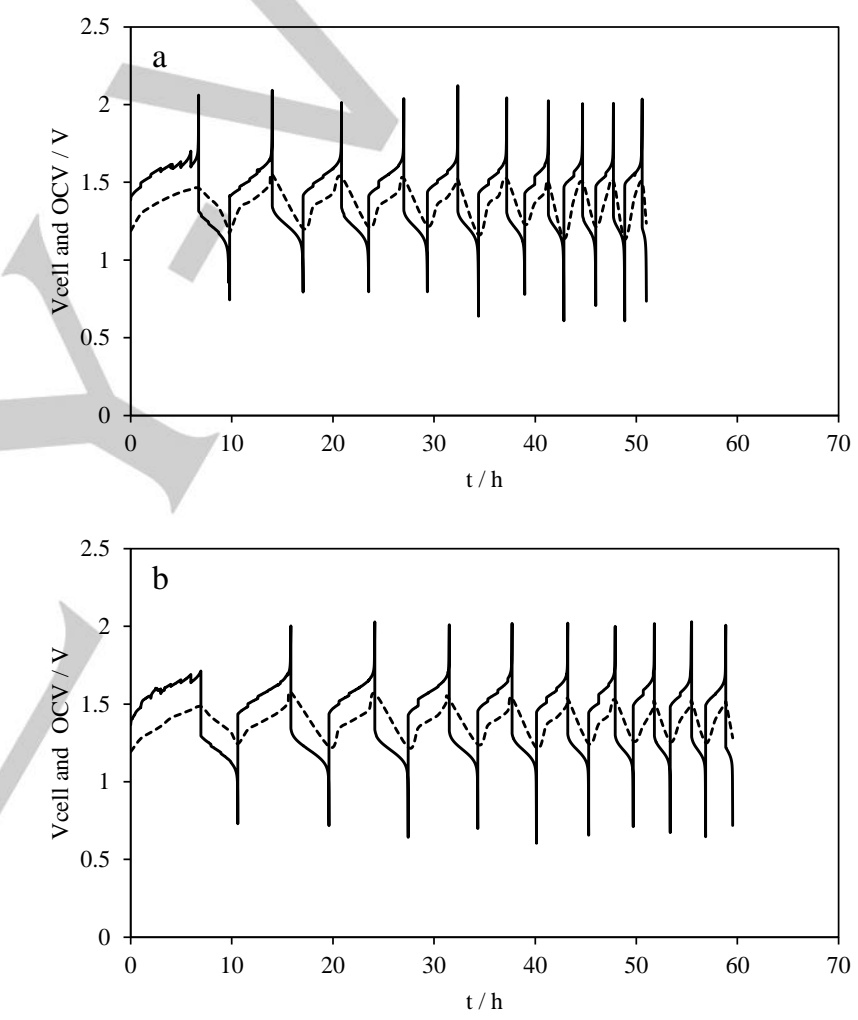

Figure 3. Charge/discharge response of VRFB during the two different tests, the standard one (a) and with nanofluids (b). Solid line: Cell voltage; Dashed line: OCV. $\mathrm{T}=30^{\circ} \mathrm{C}$.

Figure 4 shows the charge and discharge capacity along the ten cycles of the tested batteries. It can be clearly observed, the benefit of working with nanoparticles in the electrolyte. The total charges were 28.5 Ah and 32.6 Ah for the experiments carried out with the standard electrolyte and with nanofluids, respectively. This means that the use of the nanoparticles of graphene based nanoparticles in the electrolyte increased the charge capacity more than $14 \%$. From these values, the efficiencies of the battery can be determined. The equations to calculate the charge or coulombic efficiency $\left(\eta_{c}\right)$, voltage efficiency $\left(\eta_{\mathrm{V}}\right)$ and energy efficiency $\left(\eta_{\mathrm{E}}=\eta_{\mathrm{C}} \cdot \eta_{\mathrm{V}}\right)$ can be found elsewhere [7]. These efficiencies are also shown in Figure 4 . It is noticeable that both efficiencies, coulombic and voltage ones are very similar from the second to the ninth cycles. In the case of the tests with the nanofluids, the voltage efficiency was slightly high comparing with the tests performed with the standard electrolyte. Moreover, in the first and in the last cycle, the energy efficiency was much higher 
in the case of the battery running with the nanofluids. In contrast, these values were $29.6 \%$ and $20.6 \%$ for the last cycle. The energy efficiency values were $39.4 \%$ and $34.7 \%$ for the first cycle in the tests carried out with and without nanofluids, respectively. The reached efficiency values (around $60 \%$ ) are similar to others found in literature where a protonic exchange membrane is also used ${ }^{[15,16]}$. The power reaches a value of $1.8 \mathrm{~W}$ in both experiments. However, the energy was higher when graphene based powders were added to the electrolyte. It varied from 4.5 to $0.8 \mathrm{Wh}$ in the test carried out with graphene and from 3.7 to $0.5 \mathrm{Wh}$ in the standard test. A drop in the energy was appreciated with number of cycles due to the decrease of the discharge capacity, as it has been stated previously.
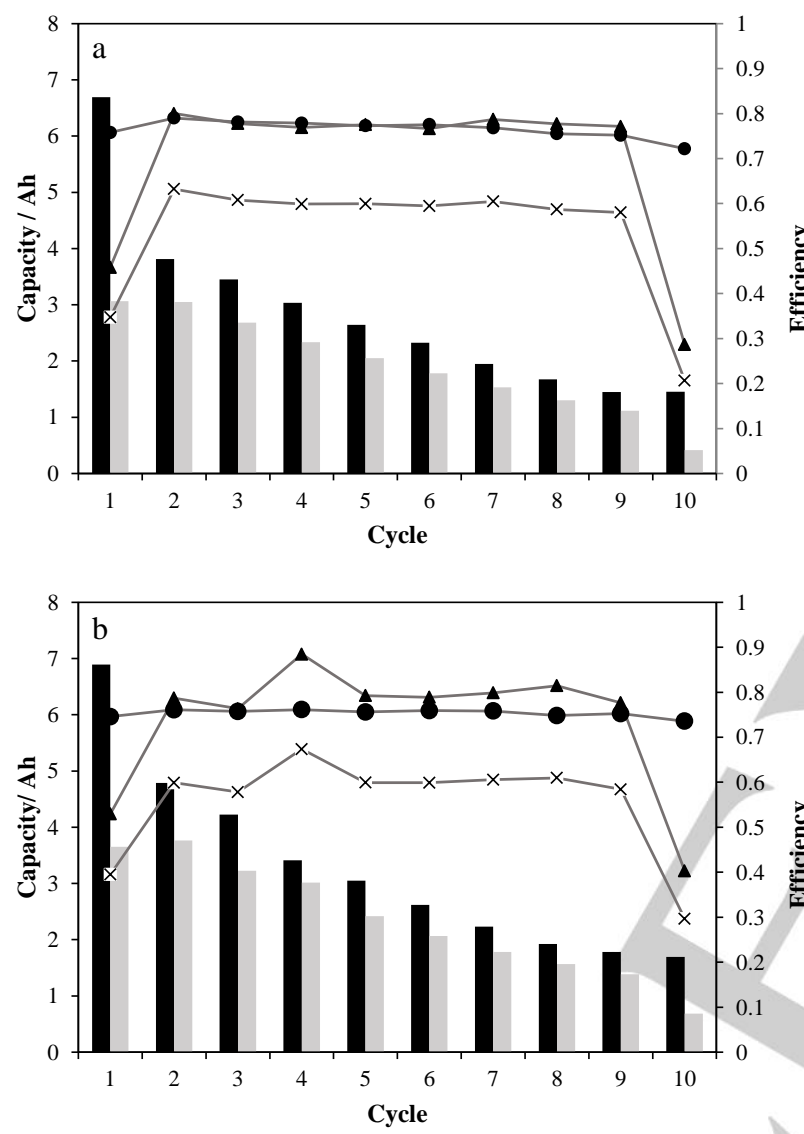

Figure. 4. Charge (Black bars) and discharge capacity (Gray bars) over the ten cycles under standard test (a) and with nanofluids test (b). Efficiencies obtained during the different essays, Coulombic efficiency $(\eta c): \mathbf{\Delta}$; Voltage efficiency $(\eta v): \bullet$ and Energy efficiency $\left(\eta_{E}\right): X$.

On the other hand, the stability of the used nanofluid is a key parameter to be evaluated for this kind of technology. Thus, the stability of the prepared electrolytes based on nanofluids with carbonaceous nanoparticles was evaluated by $Z$ potential measurements. The magnitude of the $Z$ potential is a measurement of the surface charge of particles of the colloidal system ${ }^{[17,18]}$. If all the particles is suspension have a large negative or positive $Z$ potential value, then they will tend to repel each other and there will not be tendency for the particles to aggregate and hence they will not precipitate.

Table 1 shows the $Z$ potential values of the electrolytes with and without 0.04 wt\% of carbonaceous nanoparticles and of an aqueous solution with and without the same concentration of carbonaceous nanoparticles. Moreover, the conductivity and the $\mathrm{pH}$ of the solutions are also shown. It can be observed that the electrolytes show positive values of $Z$ potential because of the presence of vanadium ions presented which have positive charge. While the electrolytes with nanofluid based on graphene nanoparticles show high negative $Z$ potential values $(-20 \mathrm{mV}$ and $-13 \mathrm{mV}$ for the anolyte and catholyte, respectively) which is indicative of high forces of repulsion and makes not easy the flocculation of particles in this media. In the case of the aqueous solutions, the conductivity was very low and the $\mathrm{Z}$ potential of the aqueous solution with $4 \mathrm{wt} \%$ of carbonaceous nanoparticles was sometimes close to $0 \mathrm{mV}$ and sometimes negative, around -11 $\mathrm{mV}$. What it was observed in the case of the aqueous solutions is that the nanoparticles precipitate after $1 \mathrm{~h}$ in the cell used for the $\mathrm{Z}$ potential measurements. These values must be considered carefully, because the $\mathrm{Z}$ potential value depends on the temperature and, above all, the $\mathrm{pH}$ and a minimum of conductivity of the media must be reached to trust in the values recorded by the equipment.

Recently, Sur et al., ${ }^{[17]}$ have obtained negative $Z$ potential values around $-55 \mathrm{mV}$ for graphene dispersion in water while Kim et al. ${ }^{[19]}$ have reported $\mathrm{Z}$ potential values around $+15 \mathrm{mV}$ of graphite particles suspension at $\mathrm{pH}$ around 3 and $-17 \mathrm{mV}$ at $\mathrm{pH}$ 9. The negative values obtained by Sur et al and also shown in this work for the electrolyte based on nanofluids with carbonaceous materials could be due to the presence of negative charged $-\mathrm{SO}^{3-}$ units in the graphene based materials as it was stated by $\mathrm{Li}$ et al., ${ }^{[20]}$. It must be pointed out that there was no sign of coagulation or agglomeration of the electrolyte based on nanofluids during the tests which is in agreement with the $Z$ potential values obtained in this work.

Table 1. Z potential, $\mathrm{pH}$ and conductivity values of different solutions measured at $25^{\circ} \mathrm{C}$.

\begin{tabular}{|c|c|c|c|c|c|}
\hline & & & Mili-Q water & $\begin{array}{c}\mathrm{V}^{+3} \text { in } \\
2 \mathrm{M} \mathrm{H}_{2} \mathrm{SO}_{4}\end{array}$ & $\begin{array}{c}\mathrm{V}^{+4} \text { in } \\
2 \mathrm{M} \mathrm{H}_{2} \mathrm{SO}_{4}\end{array}$ \\
\hline \multirow{2}{*}{$\begin{array}{l}\text { Z potential } \\
(\mathrm{mV})\end{array}$} & \multirow{2}{*}{$\% \mathrm{C}$} & 0 & $0.1 \pm 0.8$ & $4.5 \pm 1.8$ & $18 \pm 3.1$ \\
\hline & & 0.04 & $-17.7 \pm 4.2$ & $-20.5 \pm 3.8$ & $-13.8 \pm 2.5$ \\
\hline \multicolumn{3}{|c|}{$\mathrm{pH}$} & $6.0 \pm 0.1$ & $0.0 \pm 0.1$ & $0.0 \pm 0.1$ \\
\hline \multicolumn{3}{|c|}{ Conductivity $\left(\mathrm{mS} \mathrm{cm}^{-1}\right)$} & 0.001 & $265 \pm 10$ & $275 \pm 10$ \\
\hline
\end{tabular}

Finally, BET analysis were carried out to evaluate if the graphene particles clogged the carbon felt pores during the test carried out with nanofluids. Table 2 shows the specific surface area, the pores volume and the average pore radio values of the fresh electrodes and the electrodes used in the test carried out with nanofluids. Non-significant differences were observed in the specific surface areas. However, the obtained values are higher than other found in literature ${ }^{[21]}$. On the other hand, the pores volume and the average pore radio drop after being used with nanofluids. This could indicate a slight clogging effect of the pores of the electrodes. Nevertheless, it must be pointed out that a high amount of nanoparticles is necessary to get a positive effect ${ }^{[7]}$.

Table 2. Specific surface area, pores volume and average pore radio values of different electrodes.

\begin{tabular}{cccc}
\cline { 2 - 4 } & $\begin{array}{c}\text { Specific surface } \\
\text { area }\left(\mathrm{m}^{2} \mathrm{~g}^{-1}\right)\end{array}$ & $\begin{array}{c}\text { Volume } \\
\left(\mathrm{cm}^{3} \mathrm{~g}^{-1}\right)\end{array}$ & $\begin{array}{c}\text { Average pore } \\
\text { radio }(\AA)\end{array}$ \\
\hline Fresh electrodes & 13.8 & 0.0025 & 35.8 \\
\hline $\begin{array}{c}\text { Electrodes used under } \\
\text { nanofluids test }\end{array}$ & 16.0 & 0.0017 & 21.2 \\
\hline
\end{tabular}

\section{Conclusions}

It has been demonstrated, for the first time, the benefit of working with nanofluids as electrolyte in VRFBs under realistic conditions. The addition of nanoparticles based on graphene in the electrolyte of VRBs allows lower degradation rates and does not lead to lower efficiencies but slight higher voltage efficiencies. Moreover, the use of 
the carbonaceous nanoparticles in the electrolyte allows increase the charge capacity of the battery.

This work opens the research on the application of nanofluids in RFBs and much work must be performed to enhance these results and to understand better the mechanism and the role of the added solids.

\section{Supporting Information Summary}

A description of the used Redox flow battery and its main components is provided. Information about how the graphene based nanofluids were prepared is also given. Moreover, the equipments for the characterization of both nanoparticles and nanofluids and operation conditions are shown in this section. It is explained how the electrochemical tests were performed.

\section{Acknowledgements}

Financial support from the Spanish Ministry of Economy, Industry and Competitiveness and European Union through project CTM201676197-R (AEI/FEDER, UE) is gratefully acknowledged. Martín Muñoz is also thanked for the $Z$ potential measurements. M. Millán wishes to thank to the UCLM for the pre-doctoral contract with the framework of the Plan Propio I+D.

Keywords: Graphene; Nanofluid; Redox Flow Battery; Renewable Energy; Stability

[1] N. L. Panwar, S. C. Kaushik, S. Kothari, Renewable and Sustainable Energy Reviews 2011, 15, 1513-1524.

[2] P. Alotto, M. Guarnieri, F. Moro, Renewable and Sustainable Energy Reviews 2014, 29, 325-335.

[3] C. Ponce de León, A. Frías-Ferrer, J. González-García, D. A Szánto, F. C. Walsh, J Power Sources 2006, 160, 716-732.

[4] V. Pasala, K. Ramanujam, ChemistrySelect 2017, 2, 720-727.

[5] Á. Cunha, J. Martins, N. Rodrigues, F. P. Brito, International Journal of Energy Research 2015, 39, 889-918.

[6] N. Kausar, R. Howe, M. Skyllas-Kazacos, Journal of Applied Electrochemistry 2001, 31, 1327-1332.

[7] D. P. Dubal, P. Gomez-Romero, 2D Materials 2016, 3, 031004.

[8] M. Pusty, A. K. Rana, Y. Kumar, V. Sathe, S. Sen, P. Shirage, ChemistrySelect 2016, 1, 4235-4245.

[9] http://www.reinste.com/

[10] M. R. Mohamed, P. K. Leung, M. H. Sulaiman, Appl. Energy 2015, $137,402-412$.

[11] R. Lopez-Vizcaino, E. Mena, M. Millán, M.A. Rodrigo, J. Lobato, Renewable Energy 2017, 114B, 1123-1133.

[12] E. Mena, R. Lopez-Vizcaino, M. Millán, P. Cañizares, J. Lobato M.A. Rodrigo, International Journal of Energy Research 2017 (accepted)

[13] A. Tang, J. Bao, M. Skyllas-Kazacos, Journal of Power Sources 2011, 196, 10737-10747.

[14] M. Skyllas-Kazacos, J. McCann, Y. Li, J. Bao, A. Tang ChemistrySelect 2016, 1, 2249-2256.

[15] M. J. Watt-Smith, P. Ridley, R. G. A. Wills, A. A. Shah, F. C. Walsh Journal of Chemical Technology \& Biotechnology 2013, 88, 126138.

[16] P.K. Leung, Q. Xu, T.S. Zhao, L. Zeng, C. Zhang, Electrochim Acta 2013, 105, 584-592.

[17] U.K. Sur, A. Saha, A. Datta, B. Ankamwar, F. Surti, S.D. Roy, D. Roy, Bull. Mater. Sci., 2016, 39, 159-165

[18] M. Muñoz, J. Llanos, A. Raschitor, P. Cañizares, M.A. Rodrigo, Ind. Eng. Res., 2017,56, 3091-3097

[19] B.G. Kim, S.K. Choi, H.S. Chung, J.J: Lee, Particulate Scienci and Technology, 2002, 20, 95-107

[20] D. Li, M:B. Muller, S. Gilje, R.B. Kaner, G:G. Wallace, Nat. Nano. 2008, 3, 101-105

[21] T. X. Huong Le, M. Bechelany, M. Cretin, Carbon 2017, 122, 564 591.

[22] H. Zhou, H. Zhang, P. Zhao, B. Yi, Electrochimica Acta 2006, 51, 6304-6312. 


\section{Table Of Content}

The use of nanofluids based on carbonaceous nanoparticles in the electrolyte of an all vanadium Redox Flow Battery (RFB) is shown for the first time for solar energy storage. Stable suspensions were obtained and increased the performance and stability of the RFB charged using a solar energy profile. 